\title{
YABANCI SEYYAHLARIN GÖZÜNDEN FARKLI YÜZYILLARDA TÜRK YEMEK KÜLTÜRÜ
}

\author{
Prof. Dr. Hayati BEŞİRLI*
}

ÖZ: Seyahatnameler özellikle tarihçiler arasında önemli veri kaynağı olarak kabul edilmektedir. Bu eserler ilk etnografik eser olma özeliği de göstermektedir. Seyahatnamelerde tarihî ve coğrafî bilgilerin dışında ekonomik, kültürel, antropolojik, filolojik bilgiler bulmak da olanaklıdır. $\mathrm{Bu}$ eserlerde seyyah karşılaş̧tı̆̆ toplumda kendi kültüründen farklı olan unsurları daha ayrıntılı anlatmakta ve toplumsal yapı hakkında bilgiler vermektedir. Bu çalışmada yabancı seyyahların anlatılarında farklı Türk coğrafyalarındaki yemek kültürü değerlendirilmiştir. Bu değerlendirme yap1lırken coğrafi koşullar ve beslenme ilişkisi, Türk mutfak kültürünü oluşturan yiyeceklerin neler olduğunun belirlenmesi amaçlanmaktadır. Çalışmada üzerinde durulan bir diğer konuyu da gerek törensel yemeklere ilişkin ritüellerin gerekse gündelik hayata ilişkin alışkanlıkların seyahatnameler kapsamında ortaya konulması oluşturmaktadır. Çalışmada 13. Yüzyıl (Wilhelm Von Rubruk) 14. Yüzyll (İbn Battuta, Johannes Schiltberger), 15. Yüzy1l (Ruy Gonzales De Clavijo), 17. Yüzyıl (Jean-Babtiste Tavernier) ve 19. Yüzyıl (Arminius Vámbéry) seyahatnameleri incelenmiştir.

Anahtar Kelimeler: mutfak, yemek, yemek kültürü, seyahatname, Türk kültürü, Türk dünyası yemek kültürü.

\section{Turkish Food Culture from The Perspective of Foreign Itinerants' Perspective in Different Centuries}

\begin{abstract}
Itineraries are considered to be important data resources especially among historians. These are also the first ethnographic works. In the itineraries, besides historical and geographical data, economic, cultural, anthropological, philological data can also be found. In these works, the itinerants give detailed descriptions of the cultural differences between their own culture and the one they have encountered, and inform about the social structures. In this paper, food culture of the Turkic
\end{abstract}

* Kırgızistan-Türkiye Manas Üni. SBE Müdürü. hayati.besirli@gmail.com 
12

TÜBAR XL / 2016-Güz / Prof. Dr. Hayati BEŞİRLİ

world in the foreigners' narratives has beeen reviewed. While reviewing, connections between geographical conditions and nutrition, and the foods composing the Turkish cuisine will be determined. Another issue dealt with in this paper is to put forward the rituals and practices regarding the ceremonious foods and daily life respectively. In this paper, 13th century (Wilhelm Von Rubruk), 14th century (İbn Battuta, Johannes Schiltberger), 15th century (Ruy Gonzales De Clavijo), 17th century (Jean-Babtiste Tavernier) and 19th century (Arminius Vámbéry ) itineraries have been reviewed.

Keywords: cuisine, food, food culture itinerary, Turkish culture, food culture of the Turkic world.

\section{Giriş}

Arapça "gezmek, gezi" anlamındaki seyahat ile Farsça name (risale, mektup) kelimelerinden oluşan seyahatname "gezi mektubu, gezi eseri" manasına gelir. Buna Fars edebiyatında sefername adı da verilir. Arap edebiyatında "seyahat" ve "seyahatname" anlamında daha çok rihle kelimesi kullanılır. Rihle, "bir yerden bir yere göç etmek" manasındaki rahl (veya aynı anlamdaki irtihal) mastarından isim olup "göç" demektir. Eski Arap şiirinde, Kur'an'da ve hadislerde rihle "göç, yolculuk, gezi, seyahat" anlamlarında kullanılmış ve Kur'an'da Kureyş kabilesinin ticaret amacıyla yaptığı yolculuk ve seyahatler rihle diye anılmıştır (Yazıcı, 2009:9).

Seyahatnameler özellikle tarihçiler arasında ilk elden kaynaklar arasında gösterilmektedir. Bunun başlıca sebebi, bu eserlerde yer alan bilgilerin çoğunun bizzat yazarları tarafından doğrudan gözlemlenen bilgiler olmalarıdır. Bu eserler kaynak olma özelliklerinin dışında bir de içerikleri açısından zenginlik içermektedirler. Seyahatnamelerde tarihî ve coğrafî bilgilerin dişında ekonomik, kültürel, antropolojik, filolojik bilgiler bulmak da olanaklıdır. Bu bakımdan bu eserleri, kültür tarihinin temel kaynakları arasında değerlendirmek mümkündür. Klasik dönemde müelliflerin coğrafya ile ilgili olarak kaleme aldıkları kitaplar, coğrafyaya ait bilgiler bizzat tanık olduğu ve duyduğu hikâyelere ve gözleme dayanan edebi eserler haline gelmiştir. Tarihçiler için seyahatnameler birincil elden kaynaklar olarak değerlendirilmektedir ( Ağarı, 2008:1).

Yazarının gözünden dönemini yansitan bu eserlerde toplumsal yaşantıya ilişkin olarak değerlendirmelerin yapılması eseri sosyolojik anlamda önemli kılmaktadır. Çalışmamızda Türk yemek kültürü seyahatnameler incelenerek değerlendirilmiştir Çalıştığımız seyahatnameler farklı dönemlerden geniş bir Türk coğrafyasını kapsayan eserlerden seçilmiştir. Bu kapsamda, çalışmada 13. Yüzyıl (Wilhelm Von Rubruk), 14. Yüzyıl 
TÜBAR XL / 2016-Güz / Yabanc1 Seyyahların Gözünden...

(İbn Battuta, Johannes Schiltberger), 15. Yüzyıl (Ruy Gonzales De Clavijo), 17. Yüzyıl (Jean-Babtiste Tavernier) ve 19. Yüzy1l (Arminius Vámbéry) seyahatnameleri incelenmiştir.

\section{Wilhelm Von Rubruk ve Seyahat Dönemi}

13. Yüzyılda Moğol istilâsı Müslümanlar için büyük bir tehlike arz ettiği gibi Hıristiyan dünyasını içinde önemli tehlike olmuştur. Bu istilâya karşı önlem almak için Hıristiyan dünyası çeşitli faaliyetlere başlamışlardir. Wilhelm Von Rubruk, Fransa Kralı IX. Ludwig (1226-1270) tarafindan Moğollara elçi görevlendirmiş̧ir. O bu amaçla Mayıs 1253'te maiyetiyle birlikte İstanbul'dan denize açılmış ve Karadeniz yoluyla Kırım'a varmıştır. Rubruk'un seyahati esnasında Türkiye'de hüküm sürdüğünden söz ettiği Selçuklu Sultanı İzzeddin Keykâvûs (II. , 1246-1259)'tur. Elçi heyeti bir hükümdardan diğerine gönderilmiş Moğol teşkilatları vasıtasıyla uzak mesafeleri kat etmiştir. Heyet altı aydan fazla bir süre Karakurum'da kalmıştır (Rubruk, 2012: 1-9).

\section{İbn Battuta ve Seyahat Dönemi}

Dünyanın önemli gezginlerinden sayılan İbn Battuta (Ebû Abdillâh Şemsüddîn (Bedrüddîn) Muhammed b. Abdillâh b. Muhammed b. İbrâhîm el-Levâtî et-Tancî) 17 Receb 703'te (24 Şubat 1304 te Fas'ın Tanca şehrinde doğmuş ve seyahatnamelere yeni bir anlayış ve üslup getirmiş, ülke ve beldelerin özelliklerinden çok insanların ve halkların durumları, sosyal hayat, inanç ve gelenekleriyle ilgili bilgiler vermiş, bundan dolayı seyahatnamesi tarih, coğrafya ve edebiyat yönünden olduğu kadar etnografik, antropolojik, sosyokültürel açılardan da büyük bir değer taşımıştır. İbn Battuta'nın seyahatleri 725 'ten (1325) itibaren otuz yıla yakın sürmüştür. İbn Battuta'nın gezdiği yerler arasında Türkiye, Hindistan, Çin, Endülüs, Batı Sudan, Cezayir, Tunus, Libya, Misır gibi ülkeler bulunmaktadır. Gezileri esnasında tuttuğu notlar, Hindistan'da soyguna uğraması ve Kalküta Limanı'nda binmiş olduğu geminin batmasıyla zarar görmüş ve eserin yazılması bazı konularda sadece gezginin hafızasına dayandırılmıștır. Türk-Moğol tarihiyle ilgili önemli bilgiler ihtiva eden seyahatnamesi Tuhfetü' $n$-Nüzzâr fi Garâibi'l-Emsâr ve Acâibi'l-Esfâr adını taşır (Yazıcı, 2009: 9-11). Türklerin, Moğolların, Maldivlilerin hükümdarlarıyla tanışan İbn Battuta birçok ülkede kadılık makamına getirilmiş, Farsça, Türkçe bilmesi ve yolculuklarında çeşitli siyasî tecrübeler kazanması dolayısıyla kendisine bazı diplomatik görevler verilmiştir (Aykut, 1999:361-368).

\section{Johannes Schiltberger ve Seyahat Dönemi}

Münih yakınlarında bir köyde (Hollers) muhtemelen 1380'de doğmuştur. Kendi beyanına göre Macar Kralı Sigismund idaresinde Türklere 
karşı hazırlanan Haçlı ordusuna, tâbi olduğu feodal efendisi Leinhardt (Leonhard) R(e)ichartinger' in hizmetinde katılmış ve Niğbolu Savaşı'nda (25 Eylül 1396) Türklere esir düşmüştür. Sonrada Yıldırım Bayezid ile birlikte Timur'a esir düşmüştür. Schiltberger tutsak olarak Timur ve halefleri ile yirmi altı yıl kalmıştır. Esaret altında dolaştığı son ülke olan Kırım'dan yıllar sonra bir yolunu bularak kaçmayı başarmış ve otuz iki yıl süren bir esaretin ardından Kafkasya, Batum, İstanbul yoluyla Tuna üzerinden ülkesine dönmüştür (1424). Ülkesinde hâtıratını kaleme almıştır. Bundan sonraki hayatı ve ailesi hakkında bilgi vermeyen Schiltberger 1440’ta ölmüştür (Beydilli, 2009:228).

\section{Ruy Gonzales De Clavijo ve Seyahat Dönemi}

15.Yüzy1l soylularından, Ruy Gonzales de Clavijo'nın önemli bir aileden geldiği bilinmektedir. Madrid doğumludur. Ancak doğum tarihi hakkında ulaşabildiğimiz kaynaklarda bilgi bulunmamaktadır Castile ve Leon hükümdarı III. Henry’nin mabeyncisidir. İspanya'dan Timur'un sarayına elçi olarak gönderilmiştir. 1402 yılında Anadolu topraklarına ayak bastığında, Timur orduları, Yıldırım Bayezid'in ordularını, Ankara Savaşı'nda yenmiş, Anadolu'nun bir bölümü, Timurluların etkisine girmiştir. Bizans'1, Fetret Dönemi Anadolusu'nu, İran'in ve Mâverâünnehir'in Tebriz, Meşhed, Merv, Belh, Tirmiz, Semerkand, Buhara gibi büyük şehirleri görmüştür. Clavijo'nun Semerkand'a seyahati, Marko Polo'nunkinden bir asır sonra olmuştur. Sefaret heyeti durmadan yol aldığı halde, Kadis'den Semerkand'a onbeş ayda varabilmiştir. Tabii bu arada İstanbul'da zorunlu olarak beş ay kadar kalmışlardı, Timur'un saraylarını görmüştür, Seyyah, 2 Nisan 1412 tarihinde Madrid'de ölmüştür (Doğrul, 1993: 10-12).

\section{Jean-Babtiste Tavernier ve Seyahat Dönemi}

Tavernier, Anvers'ten gelip Paris'e yerleşmiş olan bir harita satıc1sının oğlu olarak bu şehirde doğmuştur. 17. Yüzyıl seyyahlarından Tavernier'in 1632'de yaptığ 1 ilk İran seyahatinde Bolu-Amasya-Erzurum-Erivan yolunu takip etmiş, 1638 'de icra ettiği ikinci seyahatinde ise Marsilya'dan deniz yolu ile İskenderun'a gelmiş, müteakiben Antakya-Halep üzerinden çöl yolunu tutup Fırat'1 takiben Necef ve Basra'ya ulaşmış, oradan İsfahan'a varmış, 1644'de ise Livorno'dan gemi ile İskenderun'a gelip Halep-Telbaşer-Birecik-Urfa-Mardin-Nusaybin-Musul-Şehrizor-Sineridic-Hemedân yolu ile Isfahân'a varmıştır. 1649'a kadar süren bu üçüncü yolculuktan sonra üç defa (1652-56, 1657-62, 1663-68) daha Şark'a giden Tavernier, Hindistan ve Endonezya'yı dolaşmış 1689'da Kopenhag'da ölmüştür (Tavernier, 1980: 1-9). 
TÜBAR XL / 2016-Güz / Yabanc1 Seyyahların Gözünden...

\section{Arminius Vámbéry ve Seyahat Dönemi}

Vambery, 19 Mart 1832 tarihinde şimdi Slovakya sınırları içinde olan, Szentgyörgy kasabasında Yahudi bir ailenin çocuğu olarak dünyaya gelmiştir. İlkokulu doğduğu köyde tamamladıktan sonra Macaristan'ın Niske (Niş) şehrinde bir manastırda eğitimine devam etmiştir. Vambery, sekiz yaşına kadar Macarcanın yanında Latince, Fransızca ve Almanca öğrenmiştir. Türkistan'a gitmek için İstanbul'a gelmiş. İstanbul'da da kısa sürede Türkçeyi öğrenmiştir. İstanbul'da kaldığı süre içerisinde İslam eğitimi de almıştır. Vambery, İstanbul'dan Trabzon'a gelmiştir. Buradan geçen kervan yoluyla İran'a gitmiş. 1863 yılında 31 yaşında iken Türkistan yolculuğuna başlamıştır. Vambery, 28 Mart 1863 tarihinden aynı yılın Kasım ayına kadar derviş kılığında Hive, Kongrat, Ürgenç, Buhara, Semerkant ve Herat şehirlerini gezerek Tahran'a dönmüştür. 28 Mart 1864 tarihine kadar Tahran'da kalmıştır. Bu uzun ve tehlikeli gezisi boyunca daha birçok yerleşim alanını görmek, incelemek; hâlâ göçebe hâlinde yaşayan toplulukları tanımak imkânı bulmuştur ( Y1lmaz, 2005:599-600, Akpınar, 2012:502, Ayan, 2011: 43-45). Vambery, 1863 yılında Semerkant'a ulaştığında, Buhara Hanı Emir Muzaffereddin ile Hive hükümdarı Seyid Muhammed Han ile tanışmıştır. Vambery, 15 Eylül 1913 tarihinde 80 yaşındayken ölmüştür.

\section{Seyahatnamelerde Türk Yemek Kültürü}

Farklı Türk coğrafyalarındaki yemek kültürü yabancı seyyahların çalışmalarına göre değerlendirilirken ilk olarak coğrafi koşullar ve beslenme ilişkisi, bu kapsamda coğrafi koşullar esasında yiyeceklerin farklılaşmasının ortaya konulması, ikinci olarak Türk mutfak kültürünü oluşturan yiyeceklerin neler olduğunun belirlenmesi, üçüncü olarak ise törensel yemeklere ilişkin ritüellerin ve gündelik hayata ilişkin alışkanlıkların seyahatnameler kapsamında ortaya konulması amaçlanmaktadır.

Genel olarak Anadolu coğrafyasında yaşayan Türklerin yemek kültürünün Merkezi Asya'daki akrabalarından farklılık gösterdiği görülmektedir. Geniş bir Türk coğrafyasını gezen İbn Battuta'nın eserinde bu fark11lıkları açıkça açıklanmaktadır. İbn Battuta seyahatnamesinde Diyar-1 Rum olarak ifade ettiği Anadolu coğrafyasına ayak bastığı Alanya'dan itibaren bolluk ve bereketten bahsetmekte ve bunu "Bolluk ve bereket Şam diyarında, sevgi ve merhamet ise Rum'da" diyerek ifade etmektedir. Eserinde Anadolu coğrafyasında yaşayan Türklerden gördüğü ilgiyi ve cömertliği sıklıkla vurgulamaktadır. Bu ilgiyi eserinde “Anadolu’ya geldiğimizde hangi zaviyeye gidersek gidelim büyük alaka gördük. Komşularımız 
kadın ya da erkek bize ikramda bulunmaktan geri durmuyorlardı" ( İbn Battuta, 2000:402) ifadeleriyle belirtmektedir.

İbn Battuta Anadolu' da ilk durağı olan Alanya'yı anlatırken “Buranın âdeti gereğince ekmek haftada bir gün pişirilir. Öteki günlere yetecek kadar ekmek yapılır... Ekmek günü erkekler sıcak ekmekler ve nefis yemeklerle çevremizi doldurdu." şeklinde ifade etmektedir. Kendilerine sunulan yiyecekler ise koyun eti, tavuk eti ve meyvelerdir. İçecek olarak da çeşitli şerbetlerden sıklıkla bahsetmektedir. Anlaşıldığına göre, Anadolu'daki beslenme geleneğinde ekmek ve meyveler önemli bir yere sahiptir.

İbn Battuta tarafindan elde edilen verilere göre, Anadolu coğrafyasından uzaklaştıkça Türklerin yemek kültüründe farklılaşmalar görülmektedir. Bu farklılıkta bulgur önemli bir besin olarak karşımıza çıkar. Seyahatnamelere, bulgur ve ürünlerinin yiyecek ve içecek olarak artan önemi bununla birlikte ekmeğin ikinci planda kalması da yansımaktadır.

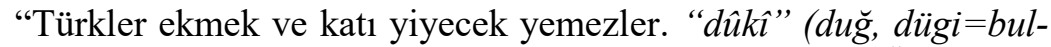
gur) adını verdikleri bizim anlîye benzer bir yemek yaparlar. Önce suyu ateşin üzerine koyarlar. Kaynayınca dûkî den bir parça içine atarlar. Yanlarında et varsa onu lime lime edip tencereye koyarlar ve beraber pişirirler. Yemek pişince herkesin payını tabaklarına koyup servis yaparlar ve nihayet tabaktaki yemeğin üzerine yoğurt dökerler” ( İbn Battuta, 2000: 466) .

Özbek Han'in bölgesindeki molalarımızda sadece düğü pişirip yiyecek kadar sürüyorduk. Yemek tek kapta pişiriliyor sonra üstüne kuru et parçaları konuluyor ve süt dökülerek yeniliyordu. Araba yoldayken herkes ya yemeğini yiyor ya uyuyordu ( İbn Battuta, 2000:519).

Tatarlar gayet cesur bir millettir. Hepsi de ata çok iyi biner. Mükemmel ok ve yay kullanırlar. Bol yemek bulunca karınlarını lüzumundan fazla doldururlar. Bulamadılar mi süt ve et ile yetinirler. Bu şekilde uzun zaman yol alır, ekmek yemeden et ve sütle yaşarlar. Tatar milleti, dünyanın bütün milletlerinden fazla soğuk ve açlı̆̆a dayanır ( Ruy Gonzales de Clavijo, 1993:141-143).

14. Yüzyılda Kırım'a ilişkin İbn Battuta’nın anlatısında da görüldüğü gibi, günümüzde Türk mutfak kültüründe önemli bir yer ifade eden buğdayın kaynatılıp kurutulması sonucu elde edilen bulgur, Karadeniz' in kuzeyinde yaşayan Türk topluluklarının beslenmesinde vazgeçilmez bir yiyecektir. 
TÜBAR XL / 2016-Güz / Yabanc1 Seyyahların Gözünden...

Ancak 19.Yüzyıl seyyahlarından Vambery'in anlatısında bu durum değişir. Seyahatname incelendiğinde tüm seyahat ettiği coğrafyalar boyunca ekmekten bahsettiği görülmektedir. Sadece halen konargöçer olan Kırgızların ekmek tüketmediğini ifade eder.

Etrek... Döndüğ̈̈nde bize çok miktarda et, ekmek ve kımı (kısrak sütünden yapılan bir ayran) dağıttı ( Vambery, 1993: 101).

Hiyve... Orta Asya'da stradan bir ziyafette bile misafirin önüne çeşitli renklerde ipekliden dokunmuş, genellikle yemek artıkları bulaşmış kirli bir sofra serilerek iki kişiye yetecek ölçüde ekmek konulması adettir ( Vambery, 1993: 114).

Hiyve... Bunun üzerine huzurda oturmam emredildi. Bir kâse çay ile bir parça ekmek ikram edildikten sonra Han benimle sohbete başladı (Vambery, 1993: 119).

Buhara... Derhal istedikleri ekmeği verdim ... Burada bulunduğum süre içinde, her yemeğimde haşlanmış et, en iyisinden ekmek, çay ve meyveler bulundu ( Vambery, 1993: 157).

Belh... Kentin pazarı birkaç ekmekçi dükkânı ile astarcı ve hazır giysici dükkânlarından oluşuyordu ( Vambery, 1993: 196).

Kırgızlar... Ekmek kelimesi bile bunlara yabancıdır. Yalnız et ve sütle beslenirler ( Vambery, 1993:153) .

Büyük Tataristan... Diğer bir âdetleri şudur: Kral sabahlart uyanınca ona altın bir kâse içinde kısrak sütü takdim ederler o da bunu aç karnına içer ( Schiltberger, 1997:117).

Benzer şekilde, bu bölgede geleneksel Türk içeceği olan kımız ve bozanın Anadolu'daki şerbetin yerini aldığı görülmektedir. Seyahatnamelerde kımız sadece tek başına içilen bir içecek değil kutlamaların da önemli bir içeceğidir. Oldukça besleyici olan ve bağışıklık sistemini güçleştiren bu içecek konuklar için aynı zamanda önemli bir hediyedir. Bu durum seyahatnamelere şöyle yansımaktadır:

Kırım... Yemekten sonra kısrak sütünden yapılan ve kımızz [=kımız] adı verilen nesneyi içerler ( İbn Battuta, 2000:466).

Sağımda solumda kımız tulumlarıyla dolu göz alabildiğince uzanan arabalar gördüm. Hükümdar yemek sonunda bu içkilerin orada bulunanlara dă̆ıtılmasını emretti ( İbn Battuta, 2000:484). 
Bunlarla birlikte, altın ve gümüş kadehler içinde şekerli kımız getirdiler ( Ruy Gonzales de Clavijo, 1993: 141-143).

19. Yüzyıl seyyahlarından Vambery ise kımıza ilişkin olarak şu bilgileri vermiştir:

Kımız üretiminde Kırgızlar ün kazanmışlardır. Bu içeceğe Orta Asya'da semirtme özelliği atfedilir ve keyif verici olarak kullanılır. Ben de kımızdan birkaç kez içtim. Ama çok ekşi olduğu için dişlerimi kamaştırdığından hiçbir zaman iki-üç yudumdan fazlasını içemedim ( Vambery, 1993:135) .

Bu nedenle bir miktar ekmek ve kurban eti toplamak amacıyla yöreyi dolaşmakta acele ediyordu. Döndüğünde bize çok miktarda et, ekmek ve kımız (kısrak sütünden yapılan bir ayran) dă̆ıttı (Vambery, 1993:103).

Hele Kırgız kadınların, kendileri de hayvan üzerinde oldukları halde, insanlara, istedikleri ölçüdeki kımızı, bir damlasını bile boşa akıtmadan, kırbaların ă̆zından ă̆ızlarına dökerek içmelerini izlemek çok ĕglenceliydi. Çünkü bu iki tarafin da yetenek ve ustallğını gösteriyordu (Vambery, 1993: 135)

şeklinde açıklamada bulunur.

Uzak Asya konar-göçer topluluklarının çoğunda tüketilen kımıza ilişkin Çin Elçisi Wang Ten-Te'nin Uygur Seyahatnamesinde 806 senesinde Uygurların Maniheist tesirlerde kımız içmekten kaçındıkları ifade edilmiştir. Bölgedeki diğer kabilelerin kımız içip sarhoş olduklarını belirtmişti (Wang ten-te, 1989: 35). Hâlen kımız konargöçer Türk toplumlarının vazgeçilmez içeceğidir. Günümüzde halen Kırgız, Kazak ve Özbek toplumlarında yoğun olarak tüketilen bu içeceği bozkır kültürüne sahip diğer göçebe topluluklarda da görmek mümkündür.

Farklı yüzyıllara ait seyahatnamelerde yoğun olarak tüketiminden bahsedilen eski bir Türk içeceği de bozadır.

Ayrıca bir çeşit şıraları da vardır ki dûkî tanelerinden yapılıyor. Kırım'dan çıktıktan sonra Sicican(Sıcgan)' a vardık. Bey çeşit çeşit yemekler hazırlatmış. Bunlar arasında ekmek te ayrı vardı. Servis yaparken önce küçük kâselerde beyaz bir su getirdiler. Herkes onu içti. "Bu içilen ne" diye sordum. Cevap verdi. "Dûkî nin suyudur" dedi. Ama onun dediğinden bir şey anlamamıştım. Yemekten çıktığım zaman bunun ne olduğunu araştırdım. Anlattılar. "Dûkî tanelerinden yapllan bir nebizdir bu. Onlar Hanefi mezhebindendir 
TÜBAR XL / 2016-Güz / Yabancı Seyyahların Gözünden...

ve nebiz onların nezdinde helaldir. Buralılar dîkîden yapılmış nebize "bûza" adını veriyorlar ( İbn Battuta, 2000: 467). 2000:469)

Arkasından kisrak sütü ve boza sunuldu ( İbn Battuta, ifadelerine seyahatnamelerde sıklikla rastlanmaktadır

Seyahatnamelerde 19. Yüzyıldan sonra çay karşımıza çıkar. Çaya ilişkin ifadelere Vambery'de rastlamak mümkündür. Vambery'nin ilk defa Türkistan coğrafyasında karşılaştığı çay ile ilişkisi sonraları zorunlu bir dostluğa dönüşecektir.

Beni görür görmez aşırı bir sevgi gösterisiyle karşılayarak gelenekleri gereğince çay adını verdikleri yeşil sudan ikram ettiler (Vambery, 2011: 27).

Vambery'de çay, uzun süren mesafelerde yorgunluk giderici bir özellik kazanacaktır. Bu durum aynı eserde "Rahat etmek üzere çayımızı hazırlamaya başladık” ( 2011: 59) şeklinde ifade bulur.

Vambery' in seyahat notlarındaki bu cümlelerin sıklığından anlaşılacağı üzere çayın İpekyolu'nu içine alan Türkistan coğrafyasındaki insanların gündelik hayatlarının yanı sıra sosyal ve ekonomik hayatını önemli ölçüde etkilediğidir. Yine Vambery’nin anlatısına göre (2011:177):

Buhara'da çayı şekersiz ve misır unuyla içyağından yapılmış bir tür çörekle birlikte içiyorlardı. Çaya üflemek edebe aykırı sayılıyor; bu nedenle, soğutmak için kâsenin içinde sallayıp çalkalamak gerekiyordu. Zarif ve görgülü bir kimse olduğunu kanıtlamak isteyen kişi, să̆ dirseğini sol elinin üzerine koyarak, bir damla bile dökmemek şartıyla, elindeki kâsenin içindeki çayl, nazikâne bir hareketle sürekli döndürmeye özen göstermeliydi. Ĕ̈er bir damla dökecek olursa, bütün ününü yitirirdi. Çay içmek, her gün, anlamsız konuşmalarla doldurulan birkaç saati alıyordu. Çaydanlık boşaldıktan sonra, içlerindeki kaynamış çay yaprakları orada bulunanlara dağttılıyordu. Ama çaydan iki parmakla tutulabilecek ölçüden fazlasını almak zarafete aykırı sayılıyordu. Erbabının demesine göre, güya bu çaylar çok güzelmiş. Bu çay meşgalesinden sonra, en büyük ĕ̆lenceleri, koç güreşiydi.

Bunun üzerine herkes sırayla salapuryanın ocă̆ında çay pişirdi (Vambery2011: 40). 
20

TÜBAR XL / 2016-Güz / Prof. Dr. Hayati BEŞİRLİ

Hacı Bilal, beni çay pazarından ya da çaycılar çarşısından geçirerek Emir'in Divan Beyi Imam Kulu Han'ın adıyla anılan sarnicın klyısına götürdü ( Vambery, 2011:157).

İçeceklerden sonra seyahatnamelerde et tüketimini değerlendirdiğimizde, at etinin Merkezi Asya'ya yaklaştıkça konargöçer Türk topluluklarının temel besinleri arasında yer aldığı görülmektedir. İbn Battuta seyahatnamesinde bu durumu,

Azak beyi Muhammed Hâce ve çocukları hizmette bulunmak için ayakta kaldılar. Daha sonra at eti ve diğer etlerden yapılmuş yemekler getirildi... Yemek bitince güzel sesle okunan Kur'an dinlendi. Bir minber kurularak vaiz buraya çıtk ( İbn Battuta, 2000:469).

Ramazan ayı içinde Sultan Üzbek'in huzurunda bulunuyordum. Sik slk yenmekte olan klsrak ve koyun eti vardl sofrada (İbn Battuta, 2000:467).

Sultan Cani Bey... Buradaki Türkler, gelen yabancıları nasıl ağırlayacaklarını, onlara ne gibi yiyecekler sunacaklarını bilmiyorlar! Kesip yemeleri için koyunlar ve atlar; içecek olarak da kımı tulumları gönderiyorlar! Önce "düki" den yapılma meşrubat sonra haşlama at ve koyun etinden oluşan bir yemek çıkarıldı (İbn Battuta, 2000:476) .

Buranın yemeği ya haşlanmış at yahut koyun etidir (İbn Battuta, 2000:484)

cümleleriyle ifade eder.

Jean-Babtiste Tavernier 1632 'de yaptığı seyahatinde Rumeli'den itibaren koyun, tavuklar, tereyağı, pirinç ve ekmek; diğer taze yiyeceklerin hediye edildiğini belirtirken ilk defa, Anadolu coğrafyasında karşılaştığ Tatarların at eti ve pastırması yediklerini anlatmaktadır.

Almons (Almus) adlı küçük bir köye varılır... Biz bu geçitten geçerken atlarımızdan ikisini kaybettik, yorgunluktan gebermişlerdi. Daha ileride rastladiğımı Tatarlara, şefimiz bu maceradan bahsedince, o kadar memnun oldular ki, içlerinden on beş, ya da yirmi kişi ölen atlarımızı parçalamak için dörtnala gittiler. İki saat sonra, onların geri döndüklerini gördük. O iki atın derisini yüzmüşler ve birer parçasını atlarının eyeri altına koymuşlardı. Bu surette et yumuşuyor ve atın hareketi ve sicakliğıyla bir çeşit pişiyor. Tatar- 
TÜBAR XL / 2016-Güz / Yabanc1 Seyyahların Gözünden...

lar, çoğu zaman, eti bu şekilde bir daha pişirmeden yerler. Tatarlardan biri, bu et parçalarından birini almış, iki kirli çamaşır arasında bir tahta parçastyla iyice dövdükten sonra oburca yiyordu (Tavernier, 1980: 28).

Seyahatnamelerde pastırmaya Schiltberger' in çalışmasında da rastlanılmaktadır:

Ĕger aceleleri varsa acele yola çıkmak zorunda iseler, Eti ince dilimler halinde kesip eyerlerinin altına koyarlar ve bunun üstünde atlarını sürerler. Acıkınca bu etten yerler. Et önce tuzlanır ve onlara göre bu et kendilerine zarar vermez. Çünkü et, atın isist ile kurur ve atın hareketi sebebiyle eyerin altında gevrekleşip, yumuşar ve suyu çıkar. Yemek hazırlamak için vakitleri yoksa böyle yaparlar (1997:117).

15.Yüzy1l seyyahlarından Ruy Gonzales de Clavijo da Timur'un sofrasında at etinin tüketildiğini belirtir.

Biz oturduktan sonra, hizmetçiler sofraları hazırlamağa başladl. Getirilen yemekler, koyun ve beygir eti idi... Gerek bu tabaklar, gerekse diğer tabaklar çok klymetliydi. Tatarlarca en makbul et, beygir etidir (Ruy Gonzales de Clavijo, 1993:141-143) .

Vambery ise,

Türkmenler... Bu sofralara oturduğumuzda, yarım sıvanmış kollarımızla birbirimizin peşi sıra kavatalara(ă̆aç gövdesinden kap) saldırarak parça parça deve ve beygir etinden oluşan bir eski zaman yemeği yiyorduk (Vambery, 1993: 74) .

Molamızın üzerinden bir saat bile geçmemişti ki, sırf sevap kazanabilmek için salih Yörüklerden birçoğu ziyaretimize geldi. Kendilerine ettiğim birkaç nefes ve hayır duaya karşılık çok miktarda ekmek, birkaç parça deve, at ve koyun eti aldım (Vambery 1993:104).

Türk kültürünün İslam öncesi döneme ilişkin kültürel değerlerden beslemesini sürdürdüğü Orta Asya' da Türkler Anadolu' dan farklı olarak at eti tüketimine devam etmektedir. Anlaşıldığı üzere 14. Yüzyılda Anadolu'da yaşayan Türklerin at eti tüketimini bıraktıkları bir dönemdir. Bunun sebebini ortaya koymak zordur. Burada bu sonucu etkileyen birinci unsur Anadolu coğrafyasının nüfus yoğunluğu ve yerleşik nüfusun fazlalığıdır. Bozkır kültüründen farklı olarak Anadolu büyük at sürülerinin yetiş- 
tirileceği geniş otlaklara sahip değildir. Bunun yanı sıra Anadolu'da tarımsal faaliyetlerin görece fazlalığı nedeniyle, geniş yayılım alanı gerektiren at sürüleri için yeterli bir beslenme ve hareket alanı yoktur. Bu yerleşiklik konar-göçer yaşam tarzını sürdürmeyi bozkıra göre daha zorlaştırmaktadır. Bunun yanı sıra iklimsel koşulların uygunluğu yeni beslenme kültürünü beraberinde getirmektedir. Atın temini ve beslenmesindeki zorluğunun yanı sıra, savaşlarda ulaşım aracı olarak artan önemi de bu kapsamda düşünülebilir.

At eti tüketiminin değişmesinde fiziki coğrafyanın belirleyiciliğinin yanı sıra kültürel coğrafyanın belirleyiciliği de kaçınılmazdır. Anadolu'daki Türklerin İslamlaşma sürecinde Farslar ve Araplarla yaşadıkları yoğun ve uzun süreli kültürel temaslar etkili olmuştur. At eti ile beslenme alışkanlığının bırakılmasında bu kültürel etkileşimin etkisi muhtemeldir. Anadolu'ya gelişle Türklerin kültürel anlamda beslenmelerinde Orta Asya'daki akrabalarının etkisi azalmış, gündelik hayat pratikleri de yoğun olarak dini ilişkiler yaşadıkları yakın komşularının etkisine göre şekillenmiştir.

Seyahatnamelerde Anadolu coğrafyasından uzaklaştıkça Türklerin at eti ve ürünlerini tüketimine ilişkin anlatılara rastlanır. Bu kapsamda at eti ve kımız Merkezi Asya'daki Türklerin aynı fiziksel coğrafyayı paylaştığı ve benzer ekonomik faaliyet yürüttüğü Moğollar için de önemli bir besindir.

Moğollar... Hepsi et tüketirler ve büyük-küçükbaş hayvanlardan geçinirler. Yazın kımı içtikleri sürece diğer yiyeceklerle ilgilenmezler... Bir öküz ya da at öldüğünde etini kuruturlar küçük parçalar halinde keserler ve güneşin altında duvara asarlar (Rubruk, 2012: 35).

Moğollar... At ve kısrak sütünden kımızı şöyle hazırlarlar... Onların yanlarına kısrakları koyup sağarlar... Süt tazeyken büyük bir tulumun veya buna benzer bir şeyin içine dökülür ve özel olarak yapılmış bir tokmakla yă̆ı çıkartılır. Bu odun alt kısmında insan başı kadar büyük olup içi oyulmuştur. Süt şimdi, şarap gibi ekşiyip mayalanana kadar kuvvetli dövülür. Geri alındığında yağda elde edilmiş olur. Sonra sütü denerler ve olmuşsa içerler ( Rubruk, 2012: 36).

Bu kültürel etkiyi yemek isimlerinde açıkça görmek mümkündür. İbn Battuta seyahatnamesinde dikkat çekici bir şekilde Anadolu'da tirit yemeğinden söz edilmekte ve tiritin başlangıç yemeği olduğu belirtilmektedir. 
TÜBAR XL / 2016-Güz / Yabanc1 Seyyahların Gözünden...

Biz böyle otururken yemek getirilirdi; küçük tabaklara konulmuşşeker ve yağla ezilmiş, mercimekten yapılma "serid"(tirit) ilk servisti. Onlar uğurlu olur diyerek oruçlarını tiritle açarlar. Bu iftarlı̆̆ın Peygamberimiz tarafindan diğer yemeklere tercih edildiğini ileri sürerek şöyle diyorlar : "Biz onun güzel âdetine uyarak yemeğe tiritle başlıyoruz”. Bunun arkasından öteki yemeklere geçerler (İbn Battuta, 2000:407).

İbn Battuta'da Kırım coğrafyasında Anadolu'daki sebzelerin yerini yavaş yavaş et, hamur kızartması almaktadır. İbn Battuta bu bölgedeki Türk topluluklarını anlatırken "burhani” den bahsetmektedir.

Türkler iyi karakterli, kuvvetli ve cesur insanlardır. Bazl vakitlerde "burhani" denilen hamur işini yerler. Bu yemek, küçük küçük kesilmiş hamur parçalarıdır aslında. Bunlar, ortalarından birer delik açılarak tencereye oturtulur. Pişirildikten sonra üzerine yoğurt dökülüp içilir (İbn Battuta, 2000:467).

İbn Battuta seyahatnamesinde adı geçen diğer bir yiyecek riştadır. Şehriyeye benzeyen rişta piştikten sonra sütle karıştırılarak çorba yapılır. İbn Battuta'da Yemeklerin sütle karıştırılmasının yanı sıra yoğurtla da karıştırıldı̆̆ı görülmektedir:

Ve nihayet tabaklardaki yemeğin üzerine yoğurt dökerler (İbn Battuta, 2000:466) .

Türkler kırbalarında taşıdıkları yoğurdu pişirilmiş dügi ile karıştırıp içtiklerinden hiç susuzluk çekmiyorlar (İbn Battuta, 2000:498) .

Pişirildikten sonra üzerine yoğurt dökülüp içilir (İbn Battuta, 2000:467).

Zira Türk kadınları yüzleri açık dolaşırlar. Bir başka kadını da aynı şekilde gördüm. Yanındaki köleleriyle pazara süt, yoğurt getirip satıyor, karşılı̆̆ında esans satın alıyordu ( İbn Battuta, 2000:471).

Aynı yiyecek Ruy Gonzales de Clavijo'nun eserine (1993:141-143) "Bir de ayran içinde kaynattıkları hububat yiyecekleri vardır." şeklinde yansımaktadır. Ayranla ilişkili olarak yapılan yemeklerden biri de aştır. Aynı eser ayran ve ayran aşı yapılışını şöyle anlatır:

Tebriz yakınlarında... Buranın ahalisi hep Türkmen idi... Bir köye yaklaştıkça, köylüler yanımıza gelerek köylerine uğramamızı rica ediyor ve getirdikleri yemekleri bize sunuyorlardı. Önce ayran 
24

TÜBAR XL / 2016-Güz / Prof. Dr. Hayati BEŞİRLİ

ve ekmek geliyor, sonra çorba veriyorlardı. Şayet geceyi de köyde geçirecek olursak, bize et de pişiriyorlardı (Ruy Gonzales de Clavijo, 1993: 122).

Gerektiğinde yalnız ayranla yetinirler. Ayranı hazırlamaları şu şekilde olur: Önce, bir kazana su doldurup tsitırlar. Su henüz kaynamamışken, peynir gibi hazırlanmış olan yoğurt, soğuk suda ezilip slviltıldıktan sonra kazana dökülür. Böylece kazan, sirke gibi ekşi bir ayranla dolmuş olur. Daha sonra küçük yuvarlaklar şeklinde hazırladıkları hamurları kazanın içine atarlar. Bunlar içindeyken biraz daha kaynayan kazan ateşten kaldırllır. Ve kazanın içindeki, kâselere doldurulur. Bir nevi çorba demek olan bu yemek, Tatarlar nezdinde çok makbuldür. Tatarlar bunu ekmeksiz ve etsiz yer ve pek hoşlarına gider. Tarif ettiğim bu yemeğe verilen isim "aş"tır" " (Ruy Gonzales de Clavijo, 1993;141-143).

Türklerde pirinç ve pilav tüketimi incelendiğinde ise 15.Yüzyıl seyyahlarından Ruy Gonzales de Clavijo, Erzincan'a Timur'un atadığı valiyi anlatırken pilavdan bahsetmektedir. Bununla birlikte Merkezi Asya'da pilav önemli bir yiyecektir.

Etler sinilere kondu. Yaklaşık yüz tane kadar tencere çıkarlldr. Bunlarin hepsi de yuvarlak ve derindi. Bu tencereler bana, süvarilerimizin giydiği miğferleri hatırlatmustt. Sinilere konan etlerden başka, tencereler de et ve pirinç ile dolduruldu. Her tabağın görüntüsü başkaydl. Vali ile bizim önümüze kurulan sofranın örtüsü ipektendi. Sofralar kurulunca herkes bunlarin etrafina toplaştı. Herkesin et kesmek için bir bıçağ ve yemek için bir tahta kaşı̆̆ı vardl. Valinin yanında, onun yiyeceği eti kesecek bir hizmetkâr bulunuyordu. Karşısında oturan iki asilzadeyi, kendisiyle birlikte yemeğe davet etti. Sira pilava gelince, bunların üçü de tek bir kaşı̆̆ı kullandılar ve aynı sahandan yediler. Kaşığı sırayla kullaniyorlardı (Ruy Gonzales de Clavijo, 1993: 76).

Çağatay çadırlarına vardı̆̆ımızda Mirza Bozar bize et ve pilav, sonra süt ve tereyağ̆ istedi. Bunlardan sonra birçok kavun getirildi. Bu memlekette kavun hem bol hem de pek nefistir. Bir de ayran içinde kaynattıkları hububat yiyecekleri vardır (Ruy Gonzales de Clavijo, 1993:122) .

Çünkü Han Hazretleri de halkının en yoksulları gibi içyağıyla pişmiş pilavdan başka bir şey yemiyordu (Vambery 1993:160) . 
TÜBAR XL / 2016-Güz / Yabanc1 Seyyahların Gözünden...

Bugün, o günleri, yani her gün şafaktan başlayarak kendimi bol içyağıyla pişirilmiş büyük bir pilav yığını karşısında görüpte sahta aç kurt iştihası içinde üzerine saldırmaya mecbur olduğum günleri hatırladıkça tüylerim ürperiyor (Vambery, 1993:114).

19. Yüzyıl seyyahlarından Vambery’de pilav aynı zamanda törensel bir yiyecek olarak da karşımıza çıkmaktadır.

Semerkant... Emir, kente girdiği gün şenlik yapılmasını emretmişti. Bu nedenle her taraftan Emir'in mutfağında kullanılan cinsten kocaman kazanlar toplanarak Rikistan'a getirildi. Bunların her birinin içine bir zembil pirinç, parçalanmış üç koyun, büyük bir tencere dolusu içyağl ve küçük bir çuval havuç doldurularak iyice kaynayıp birbirine karışması için orta bir ateşin üzerine konuldu. Çok miktarda da çay pişirildi. Yeme ve içme at başı birlikte gidiyor, hiç ara verilmiyordu ( Vambery, 1993:182).

Sözün kısası, Rahmet Bey casusların verdikleri bilgi üzerine beni suçlama imkânı bulamadı. Bu nedenle beni pilav yeme bahanesiyle huzuruna çă̆ırdı ( Vambery, 1993:162).

Türk yemek kültüründe tatlının önemi de kültürel coğrafyaya göre farklılaşmaktadır. Anadolu coğrafyasında tatlı tüketilirken Merkezi Asya’ya doğru tatlı tüketimi görülmemektedir. Bu durum İbn Batutta seyahatnamesinde değerlendirildiğinde,

Buraya geldiğimde İyec'in hükümdarl, Sultan Atabek Afrasiyab b. Sultan Atabek Ahmed'di. Burada hükümdarların hepsine Atabek, bu topraklara da Bilad-ı Lur deniliyor. Oranın âdeti gereğince medresenin esas hizmetkâr misafirleri tek tek sayar. Her birine iki yuvarlak iri ekmek, et ve tatlı sunar. Bu saydiğım hizmetlerin masrafi tamamen Sultanın vakıflarından karşılanır. Sultan Atabek Ahmed, anlattı̆̆ımız gibi iyiliksever bir insan; dünya ihtirası yok. Iç çamaşırı bile kıldan örülmüş̧ bir giysi imiş (İbn Battuta, 2000:275276).

Bize meyve tatl ve nefis yiyecekler ikram ettiler ( İbn Battuta, 2000:410) .

Limon suyundan yapılmış içine büyük tatlı parçaları atılmış bir tür şerbetle dolu altın ve gümüs taslar getirdi yanında altın ve gümüş kaşıklar vardı ( İbn Battuta, 2000:422). 
26

TÜBAR XL / 2016-Güz / Prof. Dr. Hayati BEŞİRLİ

Oradan Muğla'ya hareket ettik... Bu adam iyi kalpli, cömert bir kişiydi. Bizi sık sik ziyaret eder, yiyecek, meyve yahut tatlı hazırlamadan yanımıza gelmezdi! Bu şehirde, ileride bahsini edeceğimiz Milas hâkiminin oğlu İbrahim Bek'le görüştük (İbn Battuta, 2000:411).

Onun adı Karamanoğlu Bedreddin 'dir... Gümüş tabaklar içerisinde leziz yemekler, nefis meyveler ve hoş tatlılardan başka; mum, elbise, binek hayvanı ve çeşitli armă̆anlar gönderdi (İbn Battuta, 2000:414).

Birki Sultanı, Aydınoğlu Muhammed'dir... Limon suyundan yapılmış, içine büyük tatlı parçaları atılmış bir tür şerbetle dolu altın ve gümüş taslar getirildi, yanında altın ve gümüş kaşıklar vardı (İbn Battuta, 2000:422).

Anadolu'daki tatlı tüketiminin önemli bir sebebini Arap kültürüyle temas oluşturmaktadır. Bu kapsamda Arap kültürünün etki sahasından uzaklaştıkça tatlı tüketimi ortadan kalkmaktadır.

Tatlı yemek onlarda ayıp sayılır... Ramazan ayında Sultan Üzbek'in huzurunda bulunuyordum... O gece arkadaşlarımın yaptıkları tatlıdan bir tabak sundum sultana. Sultan sadece parmă̆ıla dokunup tatmakla yetindi, bir daha elini sürmedi! Tülük Timur'un anlattı̆̆ına göre sultan bir gün çocuk ve torunlarının sayısı kırkı bulan saygın bir kapıkuluna şöyle demiş: "Bu tatlıı yersen cümlenizi azat ederim!" Ama adam şu cevabı vermiş. "Beni öldürsen de yemem!" ( İbn Battuta, 2000:467-469) .

Ben o gün sultana bir tabak tatll götürmüştüm. Ve sadece parmă̆ını tatlıya değgdirip ă̆zına götürdü hiç yemedi ( İbn Battuta, 2000:476) .

\section{Seyahatnamelerde Sosyal Göstergeler Açısından Yemek}

Yemek bireylerin toplumsal konumlarının belirlenmesi sürecinde oldukça önemli bir yere sahiptir. Sofra bu kapsamda didaktik bir işleve sahiptir. Özellikle törensel yemeklerde bunun çeşitli göstergelerini görmek mümkündür.

Yemeğin kiminle yendiği yani sofra arkadaşı toplumsal hiyerarşi esasında belirlenir. Bu aynı zamanda bireyin saygınlık derecesini göstermektedir. Bireyin sofradaki yeri, hükümdarın sağ ve sol tarafında oturması, sofrada hizmet görme derecesi toplumsal statüsü esasında gerçekleşir. İbn Battuta bu hususu şöyle ifade etmektedir: 
TÜBAR XL / 2016-Güz / Yabanc1 Seyyahların Gözünden...

Yemek hazırland, fikıh bilginleri şeyhler ve ahılar için ayrı bir sofra; yoksullar düşkünler için ayrı bir sofra kurulmuştu. O gün hükümdarın kapısından zengin yoksul kimse geri çevrilmedi (İbn Battuta, 2000:410).

Beni görünce ayağa kalktı, elimi tutarak yanı başına sedire oturttu, Sofraya buyur etti. Yemeği bitirdikten sonra yanından medresedeki odama gittim (İbn Battuta, 2000:419).

Hükümdar efendi bir gün ikindiden sonra bulunduğumuz mıntıkaya geldi. Müderris efendi başköşede, hükümdar onun să̆ında bende müderrisin sol tarafina oturuyordum. Bu şekil oturuş Türklerin fikıh bilginlerine gösterdikleri saygının en açık ifadesidir (İbn Battuta, 2000:421).

Bunlardan biraz yüksek peyke hükümdar için kurulmuştu. Buraya geldiğimizde kendisine ait peykeyi eliyle kenara itip bizimle beraber sedirlere oturdu. Müderris fakih să̆ tarafina, kadı onun yanına, bense daha geride bir yere oturdum. Hafizlar sedirin să̆ tarafinda yer aldilar (İbn Battuta, 2000:424) .

Kesilen etler altın ve gümüş tabaklara konuyordu. Gümüş ve altın tabaklara koyun ve beygir eti konduktan sonra sıraya dizilmiş ve bunların içine çorba doldurulmuştu. Bundan sonra da ekmek dağtılmıştı. Bu da yapıldıktan sonra, oturan her iki kişiye birer çanak verildi. Timur bize iltifat göstererek iki tabak gönderdi. Her tabak gittikçe yenisi geliyordu (Ruy Gonzales de Clavijo, 1993:141-143) .

Tahtın ortasındaki minderlere sultanla büyük hatun oturdu. Săg tarafta It Küçücük ile Urduca Hatun, soldaki mindere ise Beyelun Hatun ile Kebek Hatun oturdular. Tahtın să̆ tarafina konan iskemleye veliaht Tîn Bek, sol yandakine ikinci oğul Canı Bek, bunların iki yanına dizilen iskemlelere ise emirler ve onların çocukları oturmuşlardı. Onların ardında küçük rütbeli beyler yer alıyordu. Bunlara "Ümera-yı Hezare" denilir. Yani bin kişilik birliklerin kumandanlarıdırlar. Bu şekilde protokole göre herkes yerini aldıktan sonra altın ve gümüss sofralar üzerinde yemekler sunuldu. Her sofrayı dört veya dörtten fazla kişi taşıyordu. Buranın yemeği ya haşlanmış at, yahut koyun etidir. Her emirin önüne bir sofra getirilir. Ipekli elbiseler giyen, ipekli bir önlük takan, belindeki kında koca bıçaklar ve satırlar taşıyan "Barucı" [=barıcı; parçalayıcı] gelir. Barucı, et parçalayan demektir. Her emirin bir barucısı var. Sofralar kurulunca evvela onlar hücum ederek efendileri önünde yerlerini alırlar; arkalarında tuzlu su ile dolu altın yahut gümüşten mamul 
28

TÜBAR XL / 2016-Güz / Prof. Dr. Hayati BEŞİRLİ

minik kaplar getirilir... Buralılar kemikle yan yana pişmiş eti tercih ederler yemeklerinde (İbn Battuta, 2000:484).

İkramları budur işte! Birkaç gün geçmişti, ikindi namazını sultanla beraber kıldık; ben çadırıma gitmek için kalktı̆̆ımda derhal oturmamı emretti ( İbn Battuta, 2000:476).

Bunun yanı sıra misafirlere gönderilen yiyecekler de onlara verilen değerle ilişkilendirilmektedir.

Çünkü yukarıda açıkladığım gibi, yemekten kaçınmak, adetlerine aykırı bir durumdu ve ziyafet sahibine bir tür hakaret sayılyordu (Vambery, 1993:115).

Karadeniz 'in kuzeyinde Deştikıpçak' l gezerek Sultan Muhammed Üzbek Han ile görüşen İbn Battûta, bugünkü Kazan şehri civarında bulunan eski Bulgar şehrine varmıs, "Arzızulumât”" a karanlıklar ülkesi, Sibirya) ulaşamadığını belirterek orası hakkında duyduklarını nakletmekle yetinmiştir. 10 Şevval 732'de (5 Temmuz 1332) Muhammet Üzbek Hanın düzeni. Çeşit çeşit yemeklerden yapularak zengin bir sofra kurulmuştu; ziyafete katıldık... Buradaki Türkler gelen yabancıları nasıl ă̆ırlayacaklarını onlara ne gibi yiyecekler vereceklerini bilmiyorlar. Kesip yemeleri için koyunlar ve atlar; içecek olaraktan kımı tulumları gönderiyorlar. İkramları budur işte ( İbn Battuta, 2000:476).

Seyahatnamelerde yiyecek aynı zamanda aidiyetin belirleyicisi olarak dikkat çekmektedir. Aynı dinden farklı topluluklar beslenmelerine göre ayrılmakta ve muamele görmektedirler.

Limon suyundan yapılmış içine büyük tatlı parçaları atılmış bir tür şerbetle dolu altın ve gümüş taslar getirdi yanında altın ve gümüş kaşıklar vardı. Ayrıca yine şerbetler doldurulmuş çini kâseler ve tahta kâseler vardı. Altın ve gümüş eşyaları dini kurallar ${ }^{l}$ gereği kullanmaktan sakınan kimseler çini kâseleri ve tahta kaşıkları kullanıyorlardı (İbn Battuta, 2000:422).

Sanup(Sinop) şehrinde hem hükümdarın naibi, hem de hocası olan Kadı İbn Abdürrezzak bizi konağında misafir etmiştir... Şehre geldiğimizde ahali bizim iki elimizi yana indirerek namaz kıldiğgmıza şahit olmuş. Oralılar Hanefi oldukları için Maliki mezhebini ve onun namaz kllma usulünü bilmiyorlar tabii... Bu benzerlikten ötürü bizi Şiilikle itham ettiler. Art arda sorular sordular. Onlara

1 İslam dininde erkeklerin altın eşya ve takı kullanımı yasaklanmıştır. 
TÜBAR XL / 2016-Güz / Yabancı Seyyahların Gözünden...

Maliki olduğumuzu anlatmaya çalıştıysak ta inandıramadık yüreklerine kuşku düştü. Nihayet belde yöneticisi hizmetçileriyle bir tavşan gönderdi. Bizim ne yaptı̆̆ımızı izlemesini tembih etmiş adamcağıza. Tavşanı kestirdim, pişirdim ve afiyetle yedik. Bunun arkasından hemen ăgırlamaya başladılar. Gelsin ziyafetler. Zira Rafiziler tavşan eti yememektedirler (İbn Battuta, 2000:444) .

Kadının toplumsal konumu ve sofradaki yeri ise İbn Battuta'nın seyahatnamesinde "Kadınların Erkeklerden Üstün Tutuluşu" bahsinde anlat1lir.

Hatun böyle ihtişam ve gururla ilerleyip beyin huzuruna oturmuştu. Cariyeler ise hatunun çevresinde ayakta duruyorlardl. Az sonra getirilen klmız tulumlarindan bir kadeh dolduran hatun, iki dizi üzerine çökerek eliyle beye sunmuş, bey bunu içtikten sonra hatun ayn tarzda bir kadeh içkiyi de kayınbiraderine takdim etmiști. Nihayet beyin bizzat kendisi bir kadeh kımızı kendi eliyle hatununa içirmişti. Sofra hazırlaninca yemeklerini bir arada yediler. Bey, eşine bir takum elbise takdim ettikten sonra Hatun kibarca huzurdan çıtkt. Beylerin hatunlarına gösterdikleri ilgi burada böyle! Nihayet beyin bizzat kendisi bir kadeh kımızı kendi eliyle hatununa içirmişti (İbn Battuta, 2000:472).

Kebek Hatun memnun oldu ve kımız getirilmesini emretti. O da kraliçe gibi kadehi bana kendi eliyle sundu. Onun yanından da ayrildik (İbn Battuta, 2000:478).

İslami dönem Türk kültür çevrelerinde herhangi bir işin yapılması için uygun zamanın belirlenmesinde olduğu gibi, ögünler de genellikle namaz vaktine göre ayarlanır. İbn Battuta kayıtları da bu durumu doğrulamaktadır:

Alanya... Cuma günü benimle beraber kaleye çıkarak namaz kıld. Bana ikramda bulundu ve ziyafet verdi (İbn Battuta, 2000:402).

Akşam namazını kildıktan sonra bu adam tekrar yanımıza geldi. Beraber gittik, muhteşem bir zaviyeyle karşılaştık! Oraya geldiğimizde bize çeşit çeşit yemek, meyve ve tatlı sundular (İbn Battuta, 2000:406).

Oradan namaz kilınan yere gidilir. Namazı kıldıktan sonra sultanla beraber konağına gittik. Yemek hazırlandı (İbn Battuta, 2000:410). 
30

TÜBAR XL / 2016-Güz / Prof. Dr. Hayati BEŞİRLİ

Akşam namazından sonra bana haber saldl; bahçede bir köşede, çardak altında buldum onu. ... Beni görünce ayağa kalktı, elimi tutarak yanı başına, sedire oturttu; sofraya buyur etti. Yemeği bitirdikten sonra yanından ayrilip medresedeki odama döndüm (İbn Battuta, 2000:419).

Öğleden sonra Melik Hüseyin atından inip namaz kılmış sonra da yemek hazırlanmış (İbn Battuta, 2000:560).

\section{Sonuç}

Türkler tarih boyunca geniş bir coğrafyada konargöçer hayat sürmüşlerdir. Yaşanılan coğrafyanın genişliği yemek kültürünü de zenginleştirmiştir. Bu zenginlik sadece yiyecek türlerine ilişkin değil aynı zamanda ritüellere de yansımıştır.

Türklerin yaşadığı coğrafyanın genişliği ve farklı kültürlerle temas Türk toplulukları arasında yemek kültüründe farklılaşmaları beraberinde getirmiştir. Bu farklılaşmanın sebebi coğrafi faktör esasında değerlendirilirken, mevsimsel koşullar ve fiziksel coğrafyanın üretim biçimi üzerindeki belirleyiciliği esastır. Topluluğun yaşadığı bölgenin mevsimsel koşulları değerlendirildiğinde, besini oluşturacak bitkilerin yetişme süresi ve dayanıklılığı önem kazanmaktadır. Kuzeyde yaşayan Türklerde iklimsel koşullara göre sebze ve meyve tüketimi azalmakta ve bunun yerine et, kızarmış hamur tüketimi artmaktadır. Anadolu'daki ekmeğin yerini bulgur tüketimi almaktadır. Coğrafi faktör benzer topluluklarda benzer beslenme alışkanlıklarını da ortaya çıkarmıştır. Konargöçer toplumsal yapıyı gösteren Türk ve Moğol toplumlarının yemek kültürlerindeki benzerliğin asıl sebebi budur. Ancak Türklerin Müslüman olmaları farklılaşmaları ortaya çıkarmıştir.

Türk toplulukları arasında yemek kültürünün farklılaşmasında farklı toplulukların etkisini ise kültürel temas ve geleneksel değerlerle beslenme şeklinde ifade etmek mümkündür. Anadolu'daki Türklerin dini beslenme kaynakları, İran ve Arap toplulukları olmuştur. Bu topluluklarla temas arttıkça onların yemek kültürlerinden etkilenmelerde de artış görülmektedir. $\mathrm{Bu}$ durumu at eti, kımız ve tatlının yemek kültüründeki yerinde olduğu gibi, Farsça yemek isimlerinin mutfakta yer alması şeklinde görmek mümkündür. Burada olduğu gibi Türk yemek kültüründeki farklılaşmada Ön Asya'nın Merkezi Asya'dan kültürel beslenmesinin zayıflaması belirleyici bir faktör olarak düşünülebilir. 
TÜBAR XL / 2016-Güz / Yabanc1 Seyyahların Gözünden...

\section{KAYNAKÇA}

AĞARI, Murat, (2008), “Önsöz”, İbn Hurdazbih Yollar ve Ülkeler Kitabı, Çeviri: Murat Ağarı, Kitabevi Yayınları, İstanbul.

AKPINAR, Turgut, (2012), "VÁMBÉRY, Arminius", TDV İslâm Ansiklopedisi, C. 42, Türkiye Diyanet Vakfi, İstanbul 2012, , s. 501-502.

AYAN, Ergin, (2011), “Moğol Devri Avrupalı Seyyahlara Göre Karadeniz’in Kuzeyi”, Karadeniz Araştırmaları 2011, Sayı 30, s. 43-70.

AYKUT, A.Sait, (1999), “İBN BATTÛTA”, TDV İslâm Ansiklopedisi, C. 19, Türkiye Diyanet Vakfi İstanbul, s.361-368.

BEYDİLLİ, Kemal, (2009), "SCHILTBERGER, Hans Johannes", TDV İslâm Ansiklopedisi, C.36, Türkiye Diyanet Vakfı, İstanbul, s. 228.

DOĞRUL, Ö. Rıza, (1993), 'Timur Devrine Umumî Bakış”, Anadolu Orta Asya ve Timur, Ses Yayınları, İstanbul.

Ebu Abdullah Muhammed Ibn Batuta Tanci, (2000), Ibn Battuta Seyahatnamesi, Çeviri: A. Sait Aykut. Yapı Kredi Yayınları, İstanbul.

İGİ, Özkan. (1989), Çin Elçisi Wang Ten-Te'nin Uygur Seyahatnamesi, Türk Tarih Kurumu, Ankara.

Ruy Gonzales de Clavijo, (1993), Anadolu Orta Asya ve Timur, Tercüme: Ömer Rıza Doğrul Sadeleştiren: Kâmil Doruk, Ses Yayınları, İstanbul.

SCHILTBERGER, Johannes, (1997), Türkler ve Tatarlar Arasında(1394-1427), Çeviri: Turgut Akpınar, İletişim Yayınları, İstanbul.

TAVERNIER, J. Baptiste, (1980), XVII Asır Ortalarında Türkiye Üzerinden Iran'a Seyahat, Çeviri: Ertuğrul Gültekin, Tercüman 1001 Temel Eser, İstanbul.

VAMBERY, Arminius, (1993), Bir Sahte Dervişin Orta Asya Gezisi, Hazırlayan: N. Ahmet Özalp, Ses Yayınları, İstanbul.

WİLHEM von Rubruk, (2012), Moğolların Büyük Hanına Seyahat, Çeviri: Ergin Ayan. Ay Işı̆̆ı Kitapları, İstanbul.

YAZICI, Hüseyin, (2009), "Seyahatname”, TDV İslâm Ansiklopedisi, C. 37, Türkiye Diyanet Vakfi, İstanbul, s. 9-11.

YILMAZ, Salih, (2005), “Armin Vamberyn'in Türkistan Seyahatnamesi ve Karakalpak Türklerine Dair Kayıtlar”, BELLETEN, C. LXIX, No. 255, Türk Tarih Kurumu, s. 599-628 